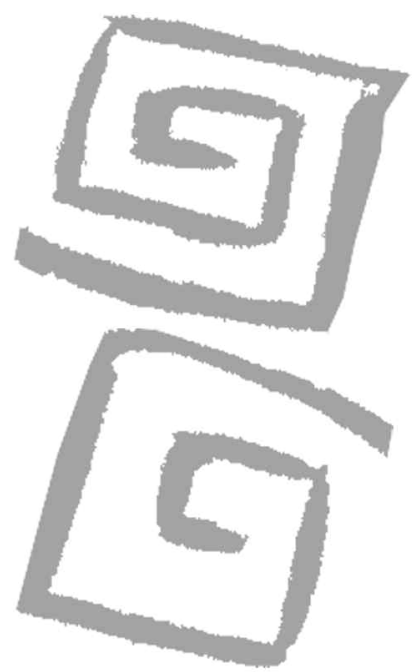

\title{
Primeros debates sobre legislación del uso de drogas en Argentina a comienzos del siglo XX: la propuesta del Dr. Leopoldo Bard y su contexto sociohistórico
}

\author{
First debates regarding the legalization of drug use in \\ Argentina at the start of the 20th century: the proposal \\ of Dr. Leopoldo Bard and its sociohistorical context
}

Sánchez Antelo, Victoria ${ }^{1}$

${ }^{1}$ Socióloga. Magíster en Empleo y Política Social. Doctoranda en Ciencias Sociales. Instituto de Investigaciones Gino Germani, Universidad de Buenos Aires. Becaria, Consejo Nacional de Investigaciones Cientificas y Técnicas (CONICET).

vsanchezantelo@sociales.uba.ar
RESUMEN Este trabajo analiza los discursos del médico higienista argentino Leopoldo Bard a partir de tres publicaciones que realizó entre 1923 y 1933 sobre toxicomanías. Las mismas condensan los debates en torno al papel del Estado, de las políticas públicas nacionales, regionales y, particularmente, la influencia norteamericana en Argentina a través de su figura. Las medidas legislativas y políticas de la época, de indudable corte represivo, fueron significativas para los avances del Estado en la esfera privada, la creciente importancia de los cuerpos profesionales en la definición de fronteras materiales y simbólicas sobre lo socialmente aceptable, incluyendo lo relativo al consumo de drogas. También se destacan los múltiples propósitos que parecen satisfacer estas políticas: en el plano local habilitan otras formas de represión de los conflictos derivados de la inmigración mientras que, en el internacional, complacen a los requerimientos norteamericanos.

PALABRAS CLAVE Control de Medicamentos y Narcóticos; Legislación Médica; Prescripciones de Medicamentos; Sociología Médica.

ABSTRACT This paper analyzes the discourses of Argentine doctor and public health professional Leopoldo Bard using three texts on drug abuse published between 1923 and 1933. These texts embody the debates of the time regarding the role of the State, public policies at the national and regional level and, particularly, the US influence in Argentina exerted through the figure of Dr. Bard. The legislative measures and policies of that time, undoubtedly of a repressive character, were key in the State's advances into the private sphere and in the increasing importance of professional organizations in the definition of the material and symbolic borders of the socially acceptable, including those related to drug use. The multiple purposes these policies seem to satisfy are also highlighted: at the local level they enable other forms of repressing conflicts arising from immigration, while at the international level they appease US requirements.

KEY WORDS Drug and Narcotic Control; Legislation, Medical; Drug Prescriptions; Sociology, Medical. 


\section{INTRODUCCIÓN}

En 1923, el Dr. Leopoldo Bard publicó Los peligros de la Toxicomanía. Proyecto de Ley para la represión del Abuso de los alcaloides (1), documento que se enmarca en los inicios de las políticas de drogas en la Argentina.

No se trató del único vocero en este debate, pero este estudio preliminar, sus argumentaciones, así como la revisión de fuentes que realiza es de incalculable valor histórico y aportan al debate actual sobre políticas de drogas en Argentina y en América Latina. Asimismo, si bien los trabajos que analizan las políticas públicas en materia de drogas son abundantes, su mayor atención suele estar centrada en el período que va de 1960 hasta la actualidad, siendo más acotadas las referencias al debate de principios del siglo XX (2-7).

El propósito de este trabajo es contextualizar la producción discursiva de Bard sobre toxicomanías en el debate más amplio en torno al papel del Estado, las políticas públicas nacionales, regionales e internacionales $y$, particularmente, los modos en que los lineamientos de la política norteamericana de aquel momento permearon los distintos discursos de la región, aspectos poco mencionados por otros autores.

Asimismo, las medidas legislativas y políticas de la época, de indudable corte represivo, resultan significativas en el debate más general en torno al papel del Estado en la salud, los avances de este en la esfera privada (8-10) y la creciente importancia de los cuerpos profesionales -sea la disciplina que fuere- en la definición de fronteras materiales y simbólicas sobre lo socialmente aceptable y no aceptable $(8,11)$, incluyendo lo relativo al consumo de drogas.

Dentro del debate historiográfico sobre la salud y la enfermedad desarrollado en Argentina $(8,12,13)$, este artículo se enmarca en las perspectivas que reconocen en las enfermedades no solo un sustrato biomédico sino además una oportunidad para desarrollar y legitimar políticas públicas, facilitar y justificar la creación y uso de ciertos dispositivos técnicos, tecnológicos e institucionales, canalizar ansiedades sociales, descubrir y tipificar aspectos de las identidades individuales y colectivas, sancionar valores culturales y estructurar la interacción entre enfermos y proveedores de atención a la salud (8).

\section{ASPECTOS METODOLÓGICOS}

Desde un enfoque cualitativo (14), se realiza el análisis de contenido (a) de las producciones discursivas (15 p.167-171) de Leopoldo Bard en torno a las políticas públicas sobre toxicomanía.

Las dimensiones que han guiado ese análisis buscan responder a los interrogantes sobre cómo caracteriza este autor el problema drogas y su correlato con el momento histórico, cuáles son los lineamientos de la política propuesta y su argumento, quiénes son los interlocutores del debate que plantea y qué grupos sociales se convierten en destinatarios de la atención estatal.

Para la delimitación del corpus, primera fase de la selección de fuentes, se utilizaron como descriptores los conceptos toxicomanía, droga, alcaloides, así como los términos utilizados para indicar la adicción a las distintas sustancias: alcoholismo, cocainomanía y opiomanía. Mientras que la segunda fase de selección se focalizó en aquellos que referían solo a legislación, dejando por fuera los trabajos propiamente biomédicos.

El trabajo se centra en tres fuentes: el documento principal para el análisis es su libro Los peligros de la Toxicomanía, ya citado; el segundo es un trabajo publicado por la Revista de la Asociación Médica Argentina en 1933; y el tercero, se trata de las actas de la I Conferencia Sanitaria Nacional de 1923, en las cuales se registra su intervención y el debate local en el ámbito médico. Estas fuentes fueron obtenidas en los archivos de la Facultad de Medicina de la Universidad de Buenos Aires entre el 6 de julio y el 20 de diciembre de 2011. Los debates legislativos se analizan a partir del texto de Guillermo Aureano (2), quien los cita extensamente, dado que no fue posible acceder a los originales (b).

Cabe aclarar que, para este artículo, que se limita a los argumentos de Bard, si bien las políticas internacionales aparecen como un aspecto central, se asume que el fenómeno drogas no se agota en las mismas. Por el contrario, dado el carácter multidimensional de la temática, 
fue preciso realizar un ajustado recorte al complejo entramado de actores, procesos e instituciones que conforman el problema drogas.

\section{EL DEBATE EN ARGENTINA A COMIENZOS DE SIGLO XX Y LA FIGURA DE LEOPOLDO BARD}

A fines del siglo XX, Guillermo Aureano trabajó extensamente sobre los alcances de la legislación argentina en lo relativo a ciudadanía y construcción social de las figuras de la adicción y del adicto. Este autor reconstruyó el proceso de objetivación por el cual se define al sujeto plausible de sanción. En el recorrido que realiza sobre la legislación argentina centra su atención en cómo, a pesar de la tradición liberal de nuestra Carta Magna, se logra la penalización del consumo de sustancias, aspecto que actualmente sigue en el centro del debate político-legal.

Ahora bien, mientras en el siglo XIX se mantenía cierta distinción entre derecho y moral, dejando los juicios sobre los excesos -derivados del consumo de sustancias- en el terreno de lo honestum $\mathrm{y}$, por tanto, no sancionable desde el derecho, en el siglo $X X$ ambos comienzan a entrecruzarse con más claridad (16 p.90-91). En ese período de transición se origina Los peligros de la Toxicomanía.

Al promediar la década de 1920 se logran impulsar dos leyes claves, ambas promovidas por el autor: en 1924 la ley 11.309, que analizaré más adelante, regula la importación, el comercio y las prácticas profesionales en las que median las sustancias y, en 1926, la ley 11.331 que se convierte en la primera tipificación de la tenencia de drogas $(2,3)$. Esas propuestas se enmarcan en los preceptos del paradigma moralintervencionista $(16,17)$ (c), inspirado en las políticas norteamericanas (16-20), que marcan los lineamientos en las convenciones internacionales y del que Bard es uno de los promotores locales (2). La esencia de este paradigma es institucionalizar la relación entre derecho y moral, que habilita la intervención del Estado en la esfera privada.

Inicio mi análisis con estos antecedentes, centrándome en la figura de Leopoldo Bard, en su contexto, sus discursos, así como en sus diálogos con personalidades académicas y políticas internacionales.

Con respecto a Bard, cabe destacar que se trató de un personaje multifacético: médico higienista, presidente del club deportivo River Plate, militante político yrigoyenista, por lo que ocupó una banca como Diputado Nacional por el radicalismo y posteriormente se convirtió en preso político del golpe de Estado de 1930. En 1947, durante el primer gobierno peronista, asumió como funcionario bajo la órbita de Ramón Carrillo (21). Su producción académico-política es abundante y sobre temas diversos, por lo que me centraré puntualmente en sus escritos sobre toxicomanías.

\section{Los peligros de la toxicomanía: proyecto de ley para la represión del abuso de los alcaloides}

Como ya señalé, se trata de un documento preliminar de carácter informativo, dirigido a apuntalar los argumentos del legislador higienista en su presentación de 1923, en el marco del debate tendiente a modificar la legislación vigente relativa al uso de alcaloides.

En el documento pueden distinguirse dos líneas argumentativas. La primera, bastante confusa y fragmentaria, donde establece sentencias trágicas sobre cuadros clínicos presentados en ateneos médicos, a partir de los cuales ensaya hipótesis sobre las posibles causas de la apetencia por los alcaloides. Introduce argumentaciones sobre la necesidad de definir la figura legal del toxicómano. Enumera los factores que producen esta inclinación, señalando aspectos tan variados como lo puramente individual, hasta aquellos que involucran la dimensión social, así como procesos culturales de orden mundial. Para dar sustento a sus afirmaciones se vale de recursos tales como: informes de la policía; artículos de periódicos nacionales e internacionales, principalmente norteamericanos y europeos; fuentes académicas internacionales, a través de las cuales presenta los distintos cuadros clínicos de toxicomanías: morfinomanía, cocainomanía, etc.; relata además el origen de las sustancias, las condiciones para el uso médico y las consecuencias que acarrea el abuso. Finalmente, para cerrar su documento, presenta las implicancias de 
estas prácticas en la Medicina Legal, relata una síntesis de la legislación internacional y local, e incorpora opiniones de algunos expertos de distintos países.

En la segunda línea argumentativa de su documento es donde puede identificarse la propuesta legislativa que impulsa. Si bien es la parte más acotada, es la que contiene las propuestas concretas que justifican su exposición. La desproporción entre un contenido y otro no salta a la vista si solo se atiende a los sucesos locales. A mi entender, si se analizan los diálogos que establece con agentes locales e internacionales del momento, se logran algunas claves para entender el empeño de Bard en remarcar la alarma social que representan las toxicomanías.

\section{El problema de la legislación vigente}

Su propuesta sugiere modificar los Artículos 204 y 205 (d) del Código Penal, sancionado en 1921. Según expone nuestro protagonista, en el Artículo 200 y su complementario 201, ya se castiga el tráfico y/o comercio de productos, aguas y/o sustancias alimenticias adulteradas, todo lo cual queda contenido en los delitos contra la salud pública. Sin embargo, considera que no pueden englobarse a sustancias tan nefastas como los alcaloides con el mismo rótulo que los alimentos, aguas y medicamentos.

Coincido con Aureano (2) cuando afirma que la historia oficial se equivoca al ubicar en el Código Penal de 1921 el surgimiento del tema droga en las políticas públicas argentinas. Como indica la historia de la farmacopea local, los primeros intentos de reglamentación y control de drogas y medicamentos datan de 1822 . Promediando el siglo XIX, se impulsan las primeras asociaciones profesionales farmacéuticas que fueron precursoras de la futura farmacopea nacional. Su segunda edición será la Ley Nacional No 4.687 sobre el "Ejercicio de la Farmacia y su Reglamentación" de 1905 (22 p.4). El trabajo de Bard refiere, en numerosas ocasiones, a las dificultades que ha generado la falta de reglamentación de esa ley, argumento que le permite demostrar cómo su propuesta - centrada en modificar el Código Penal- viene a complementar esta normativa, la que considera un tanto laxa para prevenir la expansión de la toxicomanía. Así, destaca que el código vigente no impide

...que los vendedores de alcaloides para uso ilegítimo sean puestos en situación de no poder dañar nuevamente a la sociedad. (1 p.11)

Cabe recordar que existían otros antecedentes en materia de drogas, como la Orden del Departamento Nacional de Higiene de 1919 sobre la venta de alcaloides (1 p.30), o los compromisos tempranamente asumidos por nuestro país en el plano internacional, como la adhesión a la Convención de La Haya de 1911-1912. Los lineamientos de esta última se efectivizaron localmente con un decreto firmado por el presidente Marcelo T. de Alvear en 1922 (1 p.33). Estos antecedentes, sobre los que me detendré más adelante, también están presentes en los debates y reflexiones de la época, así como en los planteos de Bard.

Ahora bien, concretamente, la propuesta de 1923 está dirigida, en primer lugar, a penalizar a quienes vendan o entreguen sustancias estupefacientes sin prescripción médica o en cantidades que superen lo indicado por la especialidad farmacéutica. En segundo término, esa penalización debería hacerse extensiva a quienes introduzcan al país estas sustancias por vía clandestina, a través de contrabando, falseando declaraciones, etc. (1). Esto ubica su proyecto, por una parte, en los debates más amplios -que exceden el ámbito local (23)- sobre las funciones del Estado en la salud pública, específicamente tendientes a regular el ejercicio de las ciencias médicas y actividades afines (24 p.154); y, por otra, en el plano de las relaciones comerciales internacionales y sus mecanismos de regulación.

\section{El debate entre los cuerpos médicos}

Durante la I Conferencia Sanitaria Nacional de 1923, en la sesión referida a toxicomanías, se informa acerca del envío a la cámara de Diputados de la Nación de un proyecto de ley, de alcance nacional, orientado a la regulación del tráfico, comercialización y dispensación 
de alcaloides. Este proyecto sistematizaba diversas propuestas y legislaciones provinciales vigentes. Según consta en el acta de la sesión, la exposición de Bard se centró en detallar las modificaciones al Código Penal necesarias para sancionar a quienes venden de forma irregular estos productos (25 p.46).

En esta oportunidad, es destacable la propuesta del representante de la Sociedad Nacional de Farmacia, Dr. Gabriel Meoli, que recomienda "...sustituir las multas que son ineficientes, por penas corporales enérgicamente aplicadas [y así] persuadir a los colegas que se ven involucrados en tan funesto vicio" (25 p.47). Sin embargo, expresa su desacuerdo con los planteos que hacen caer toda la responsabilidad en los profesionales de farmacia, por lo que sugiere la inclusión de una fórmula en la redacción del texto legislativo que indirectamente habilita a la penalización del consumo. Esta será retomada por Bard en 1926 con la sanción de la ley que la hará efectiva:

[se] declara comercio ilegítimo, sin admitir prueba en contra, la existencia de alcaloides en personas no autorizadas, castigando a las infracciones a la ley y reglamentación, con prisión [...] e inhabilitación si es profesional. (25 p.87)

Aun así, en 1923, la preocupación parece estar concentrada en la regulación de la actividad profesional de médicos y farmacéuticos. Todo el debate se basa en enumerar las experiencias provinciales sobre la regulación del comercio, distribución y venta, lo cual evidencia la falta de una mayor coordinación nacional, dificultando los controles sobre el contrabando o la homogeneización de criterios en las sanciones y regulaciones. Respecto a los comercios y profesionales habilitados para manipular alcaloides, por propuesta de la Sociedad Nacional de Farmacia, se sostiene que "se limita a los establecimientos debidamente autorizados, contraloreados por las autoridades sanitarias" (25 p.47).

Los interesados en delimitar el ámbito profesional no son solo los farmacéuticos. Los representantes provinciales también apuntaban a ampliar las regulaciones profesionales: la propuesta de un senador cordobés, por ejemplo, dotaba de poderes a las autoridades sanitarias provinciales para regular la distribución, además de requerir una detallada contabilidad sobre los usos y el tráfico de estas sustancias indicando los agentes involucrados, cantidad por sustancia y usos (1 p.714-716). Como se verá más adelante, son todas medidas sugeridas por las convenciones internacionales.

La votación final de la I Conferencia Sanitaria Nacional no solo respaldó la propuesta de Bard, sino que promovió el apoyo de esas reformas mediante el patrocinio de la corporación sanitaria en la Cámara de Diputados (25).

\section{LOS DIÁLOGOS INTERNACIONALES DE BARD}

Se sabe que las trayectorias individuales no alcanzan para explicar la historia, pero son nodos por los que circulan los discursos promotores de aquellos procesos sobre los que se busca reflexionar (12). En este caso, Bard es la excusa para agregar complejidad a los intercambios discursivos de la época. Desde esta lógica revisten mayor importancia los diálogos que estableció y la influencia de estos en sus planteos.

En 1933, en una secuencia de artículos publicados en la Revista de la Asociación Médica Argentina, hace pública una encuesta a distintas personalidades internacionales del ámbito académico y político: el profesor Flamino Favero, de la Facultad de Medicina de San Pablo; el profesor Dr. Enrique Roza, de la Facultad de Medicina de Río de Janeiro; el Dr. Eduardo Blanco Acevedo, profesor uruguayo y el Sr. Harry Anslinger, Director de la Agencia Federal de Narcóticos de EE.UU. (26).

Los ejes de las preguntas refieren a la legislación vigente en el país del interlocutor, indagando sobre el perfil de los toxicómanos y de los traficantes, así como sobre los ambientes y factores que difunden la toxicomanía. Reclama comentarios sobre el actuar de la Liga de las Naciones que, en 1931, impulsó una serie de medidas de coordinación internacional. Estos intercambios pueden darnos pistas sobre los diálogos entre lo local y lo global que ya estaban presentes en su proyecto de 1923. 


\section{Sobre los sujetos, los contextos y el problema de los "médicos indignos"}

Cuando Bard solicita a sus colegas sudamericanos que caractericen a los toxicómanos y los traficantes de sus respectivos países, es destacable cómo hacen referencia a un mismo estereotipo: respecto a los primeros, se trata de sujetos de las clases sociales más elevadas, "las personas más desocupadas", afirma uno de los brasileños, los jóvenes de los grupos más cultos: los niños bien (26 p.1185); mientras que los traficantes, según estos expertos, suelen ser los empleados de cabarets, de las pensiones chics en Brasil o de los bares alemanes en Uruguay. Los facilitadores necesarios de este tráfico son las prostitutas, o cocottes, y los mozos de café, pero también los empleados de farmacias. Se trata de focos que "irradian vicio", afirma el uruguayo (26 p.1186-1188), coincidiendo con las caracterizaciones que realiza el diputado radical, al otro lado del Río de la Plata:

\footnotetext{
Son numerosas las personas que en Buenos Aires se ocupan del infame comercio: farmacias donde se da un "santo y seña" a los clientes, agencias de lotería y de quinielas, casas de modas y de "coiffure", vendedores de localidades para teatros, etc. (1 p.15)
}

Entre los que difunden la toxicomanía, además de los ámbitos "perniciosos relacionados con el vicio", los profesionales sudamericanos coinciden en afirmar que revisten de gran peligro "...los médicos indignos que se sirven de su profesión, para fomentar el vicio" (26 p.1185).

En opinión del representante paulista, la legislación de su país, que parecía excesivamente severa para algunos, a su parecer resultaba "excelente ya que no molesta a los honestos y fiscaliza eficientemente a los deshonestos". Su preocupación se centraba también en la necesidad de reprimir a los profesionales, muchos de los cuales además "caen en el vicio y lo difunden". Afirma que "en Brasil los médicos viciosos son muchos, como en el extranjero. Es la eterna esclavitud de la moda de afuera" (26 p.1185). Y concluye:
Se sabe que la producción excesiva de tóxicos, es mayor que las necesidades. Este exceso tiene consecuencias, ciertas facilidades de tráfico. Por ello los contrabandos. Esto obliga a crear modas de consumir, lo que es excesivo. (26 p.1185)

Complementariamente, el profesor de Río de Janeiro informa que en Brasil, para 1931, se había sancionado una ley -puesta en vigencia en 1932 mediante el decreto 20.930 (19 p.65)que permitió la fiscalización de la venta y "vigilancia de los viciosos", logrando que la Sanidad Pública de su país obtenga el control de las recetas de morfina, éter, cocaína, etc. Sin embargo, según el profesor carioca, este control dificulta excesivamente el acceso a quienes requieren honestamente estas sustancias (26).

Por su parte, el profesor uruguayo señala que en su país la legislación de 1914 se basa en la ratificación de la Convención de La Haya, lo que implica, en términos de contenido, seguir la misma línea de acción que en el caso brasileño.

En su respuesta, el director de la Oficina de Narcóticos en Washington, Harry Anslinger, recomienda a Bard:

Un código penal debiera, naturalmente, imponer severas penalidades a los traficantes de drogas narcóticas, ya fuera el traficante un simple vendedor ambulante o un médico que hubiera prostituido su profesión por sórdida ganancia. (26 p.1327)

En 1914 se aprueba en EE.UU. la Ley Harrison, una severa regulación que exigía el registro de todos aquellos -principalmente médicos y farmacéuticos- que importaran, produjeran, traficaran -a nivel inter e intra estados- o vendieran opio y hojas de coca, así como cualquiera de sus derivados. Determinadas sustancias se restringen así al ámbito profesional, oportunamente registrados en una agencia controlada por el Gobierno Federal y previo pago de impuestos (25 p.200). Anslinger destaca la efectividad alcanzada por las leyes en su país:

Como resultado de la sanción de estas leyes federales sobre narcóticos, yo creo que la Oficina puede justamente decir que el escape de los propios conductos médicos a usos no médicos ha 
sido extensamente reducido durante los últimos 15 años; que ha habido una reducción substancial en el número total de efectos no-médicos a las drogas narcóticas; y que el contrabando y el tráfico ilícito interestatal en narcóticos han sido fuertemente disminuidos. Esto ha sido notable durante los últimos años, cuando este Gobierno ha tenido el beneficio de una cooperación internacional más extensa. (26 p.1324) (Cursivas del original)

Tal como afirma el funcionario americano, la mayor efectividad interna de las políticas de su país se debe también a la cooperación de los demás países en la adopción de medidas locales. Las posturas sudamericanas, coincidentes con los lineamientos norteamericanos, parecen estar centradas en resguardar la moralidad profesional, pero también en resaltar una pauta de la toxicomanía: es una moda que se contagia.

\section{Sobre el contagio}

Queda claro que el problema no son solo los médicos. Si recordamos lo afirmado por Armus (10) sobre cómo las enfermedades canalizan ansiedades sociales, no son casuales algunas afirmaciones de estos facultativos. Frente a la pregunta sobre los factores que han concurrido para la difusión del mal, el profesor Blanco Acevedo diagnostica:

\footnotetext{
La toxicomanía ha aumentado en el país como consecuencia del fenómeno social de la post-guerra que tan honda repercusión ha tenido en los pueblos de occidente. Esa claudicación moral de ciertos núcleos sociales, y la falta de una severa ley de inmigración, hasta hace poco más o menos un año y medio, fueron factores fundamentales para la difusión del mal. (26 p.1186)
}

Los cambios acaecidos con el proceso inmigratorio de comienzos del siglo $\mathrm{XX}$ motorizaron un sinfín de transformaciones sociales, urbanas y políticas (12 p.21). La inmigración se vuelve así foco de atención y chivo expiatorio de toda tensión que trastoque la armonía social fantaseada por las elites de los países receptores. De los barcos no solo bajan personas, sino también ideas e infecciones morales. Así “...las profundas conmo- ciones sufridas por los países europeos" se explican por la relación que estas guardan "...con los desequilibrios psíquicos experimentados por sus masas sociales." Afirma Bard:

Roto el freno de las viejas disciplinas morales, embotada la capacidad de resignación, que es la única defensa conocida para las miserias humanas, exacerbamos los anhelos ambiciosos sin medios correlativos que tiendan a asegurar su realización, el desequilibrio se produce con fuerza tan irresistible en lo moral como en lo político. [...] Mientras temperamentos impetuosos y ardientes corren tras sueños confusos por el camino de las agitaciones revolucionarias, los caracteres escépticos y apagados buscan ahogar sus desengaños en el letargo de una embriaguez desfalleciente. (1 p.13)

¿Por qué relacionar las toxicomanías con los procesos migratorios? No es casualidad, ya que las políticas de drogas no refieren a procesos internos, sino que amalgaman el discurso internacional con necesidades locales. Así, la asociación entre sujetos de dudosa moral, grupos sociales marginados y consumo de drogas no es una exclusividad estadounidense (28 p.96, 29). Thiago Rodrigues, al observar la experiencia brasilera de comienzos del siglo XX, la sintetiza de esta forma:

\footnotetext{
...essa massa amedrontadora era conformada por negros, imigrantes e migrantes rurais, socialistas, anarquistas, ladrões, prostitutas, operários, mulheres, homens e crianças de "hábitos exóticos e nãocivilizados"; eram eles a antítese do progresso e das maravilhas do mundo moderno. (28 p.96)
}

Cabe recordar que, para la historia de la legislación internacional en materia de drogas, la Convención de La Haya de 1911-1912 es la que se instala con mayor fuerza como moduladora de las legislaciones locales tendientes a la criminalización de los consumidores. Si bien esto no se cristaliza expresamente en los acuerdos alcanzados, la campaña norteamericana generó un fuerte cambio en las formas en que se percibía a los consumidores hasta ese momento. Es en este debate internacional que se instala el pasaje del estigma social del consumidor: del holgazán, 
débil de carácter o víctima, etc., a la figura del criminal (27 p.197-199, 28 p.93). En las distintas regiones, este discurso se irá instalando y será el inicio para que, al menos discursivamente, no solo se criminalice a los adictos (más que a la adicción), sino que

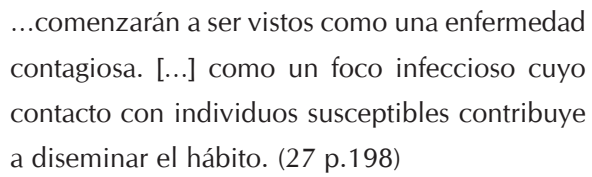

Cabe destacar que, en términos cuantitativos, según los expertos consultados por Bard, el número de casos, tanto en Brasil como en Uruguay, era reducido y no suponía una preocupación significativa hasta el momento en que las tendencias internacionales sugirieron lo contrario. La conclusión a la que llegaron era muy sencilla: mejor actuar preventivamente para evitar el contagio (26 p.1186).

\section{La acción internacional con impacto local}

En el marco de la expansión de la política prohibicionista norteamericana, en 1909 y con el patrocinio de Roosevelt, se había realizado en Shanghai la Convención Internacional del Opio, que precedió a la de La Haya de 19111912. Ambas reuniones estuvieron estrechamente marcadas por la política doméstica estadounidense. A modo de ejemplo, antes de asistir a Shanghai, el gobierno norteamericano aprueba la "Ley de Exclusión del Consumo de Opio" de 1909 que prohíbe la importación y el consumo interno de esta sustancia para usos no medicinales $(26$ p.1322, 28 p.93) a los fines de presentar sus exigencias a los demás países "predicando con el ejemplo" (27 p.196, 28 p.93).

El representante norteamericano, tanto en Shanghai como en La Haya, era un misionero de la Iglesia Metodista en Filipinas, obispo ultraconservador, con un profundo compromiso con la expansión de las políticas norteamericanas en la persecución de los "espíritus débiles del círculo insano en pos de los placeres" (27 p.192-193, 28 p.93).

Anslinger, el interlocutor elegido y elogiado por Bard en su artículo, representa esta filosofía respecto de las políticas de drogas, pero devenida en acciones institucionales orientadas al control del tráfico internacional de sustancias, primero de alcohol -durante su jefatura en una división de la Agencia de la Ley Seca- y posteriormente de narcóticos. Su figura, y el poder que le otorgó el gobierno federal de su país, encarna lo que será la política internacional norteamericana a partir de ese momento y perfila la nueva y más lucrativa empresa capitalista: la lucha contra el narcotráfico. Anslinger es quien funda, en 1930, la red de inteligencia norteamericana orientada a controlar el comercio y tráfico de narcóticos en todo el mundo (27 p.237-250).

Cuando Bard interroga al funcionario norteamericano sobre la regulación internacional, resultado de la Convención de Ginebra realizada en 1931, de la cual el gobierno norteamericano fue promotor y fuerte "cooperante" (26 p.1329), este afirma:

\footnotetext{
...el principal tráfico ilícito era pues la superproducción extranjera de esta sal [clorhidrato de morfina] y su subsiguiente introducción en los Estados Unidos [...]. En razón de mejores facilidades de coacción en el país y con la ayuda de una cooperación internacional, más completa, el contrabando de todas las drogas en los Estados Unidos durante los últimos años ha sido seriamente restringido. (26 p.1326)
}

La política preventiva interna concentra sus esfuerzos en reducir el tráfico a los canales médicos bajo la lupa del gobierno federal (26 p.1323). Mientras que la política preventiva externa se basa además en "incitar vigorosamente" a los demás países a adoptar medidas similares, así como a fijar en el plano internacional un comité de expertos que evalúe las cuotas de producción local de sustancias y cultivos de los que derivan los narcóticos, y se encargó de regular las autorizaciones para esta producción. Para luchar contra la afición a estos productos el funcionario estadounidense le responde:

Esta Oficina tiene la impresión que la adopción general [por parte de unos 40 países] y la fiel observación de los términos de esta Convención [de Ginebra de 1931], representa no solamente medios efectivos para la lucha contra la afición, 
sino el paso más importante tomado en los últimos años, hacia una acción internacional concentrada contra el tráfico mundial de drogas ilícitas. Su efecto se está sintiendo ya en lo que respecta al contrabando desde Europa a los Estados Unidos. Los así llamados países, víctimas de superproducción de manufactura extranjera, sentirán especialmente los efectos benéficos de la vigencia de la Convención. (26 p.1328-1329)

En esta misma línea, en una de las comisiones de la Liga de las Naciones reunida en Ginebra en 1923, los representantes norteamericanos realizan una fuerte campaña para coordinar y homogeneizar internacionalmente acciones que hasta el momento venían realizando los países por separado. Finalmente, en la Convención Internacional de Ginebra de 1931, EE.UU. logra imponer los términos de los acuerdos alcanzados. Será la Liga de las Naciones a través de un comité de expertos, apoyado y conformado por delegados norteamericanos, quien asesore a los países y supervise el cumplimiento de estos (27).

El cono sur no se mantenía al margen de estos procesos. En los relatos de los interlocutores de Bard se destaca que en Brasil y Uruguay se adoptaron las medidas promovidas tanto por La Haya (1912) como por la Liga de las Naciones (1931) aunque no respondieran a las necesidades epidemiológicas internas (26 p.1185-1187). Como indica Sergio Vidal, para las autoridades brasileñas la cuestión de las drogas era una preocupación ya en 1921 cuando buscaban alinear la política interna con las posturas de EE.UU. en la Liga de las Naciones. Según el autor esto se debía más a la estrecha relación comercial entre ambos países que a las preocupaciones o demandas internas (19 p.65).

Así toman sentido las afirmaciones del historiador inglés Richard Davenport-Hines, cuando sostiene que los resortes de las transformaciones en la legislación mundial durante esa época, se pueden rastrear en los procesos de la política interna norteamericana, los actores participantes y en el modo en que estos se articulan y proyectan en el mundo $(23,27)$.

Mientras las acciones internacionales son las que logran motorizar los proyectos locales, son también el puntapié inicial para el desarrollo de legislaciones que satisfacen otras necesidades internas, como atender a los conflictos generados por los contingentes de inmigrantes. Para Bard, la adopción de las normativas internacionales se torna un imperativo ya desde 1923:

En todos los países civilizados se ha sentido la necesidad de esta legislación especialísima y son muy pocos los que han dejado de Ilenarla [la hoja de la legislación]. La inclinación a los excitantes tóxicos es un fenómeno universal, cada vez más difundido. No podemos decir que nuestro país haya permanecido libre de contagio, aun cuando no se encuentre entre aquellos donde el mal acusa mayor virulencia. (1 p.12-13)

De no impulsar políticas que atiendan el avance de este funesto mal "nos expondremos, por puro descuido, a los pavorosos efectos que Ileva consigo" (1 p.13).

\section{A MODO DE CIERRE}

En su trabajo, Aureano (2) sostiene que si bien Argentina adopta acuerdos internacionales, no tiene una participación activa en los mismos. Esto se evidencia, según el autor, en la "falta de urgencia" de nuestro país en ratificar estos compromisos: recién en 1947, a través de la Ley 12.912 del 26 de diciembre, revalida el convenio de La Haya junto con los de Ginebra de 1925 y 1931. Entre las explicaciones que encuentra Aureano están, por una parte, la dificultad de las organizaciones internacionales para convencer a los países con mayor oposición a estas regulaciones entre los que estaría la Argentina (20); y, por otra, por la posición marginal de nuestro país tanto en el tráfico como en la producción de las sustancias. Así, concluye, estas dos circunstancias, muy marcadas en el comienzo del siglo XX, demuestran que las leyes sobre drogas giraron más en torno a razones de política interna que a una presión internacional (2).

Esta conclusión puede ser aplicable, en parte, si atendemos a los cambios legislativos concretos. Sin embargo, nuestro recorrido por las preocupaciones de Bard desde 1923 y los diálogos que este abre en 1933 con personalidades regionales y de EE.UU. así como los contenidos de sus 
propuestas, parecen reforzar la idea de la influencia norteamericana en el sur continental $(11,19,28)$.

Sin ser esto un factor explicativo determinante, coincido con Eduardo Vargas (23) en su reflexión sobre la experiencia brasileña: los modos de abordar la regulación local en los distintos países cuentan, con extrañas excepciones, con algunas coincidencias en las temporalidades así como en los ejes sobre los que la legislación hace hincapié. Coincidencias que no se comprenden si la mirada solo se centra en los procesos internos.

En este sentido, en los trabajos de Bard se tornan visibles las múltiples corrientes ideológicas que operan durante su época, exponiendo a los analistas a capas muy resbaladizas (12) y que Ilevan a pensar en los múltiples agentes sociales encargados de ejecutar y conceptualizar la política moral de un momento histórico.

En primer lugar, el mal ejercicio de la profesión médica o farmacéutica debería ser severamente sancionado ya que se trata de prácticas que ponen en cuestión la legitimidad social de las mismas. Así, el uso de sustancias como morfina, cocaína y éter en la práctica profesional, coloca a estas especialidades en un delgado límite entre la legalidad y la ilegalidad, entre curar o inducir al vicio. En 1923, es este límite el que parece estar en el centro del debate.

En segundo lugar, si bien su mirada se focaliza en la regulación de las políticas de comercio internacional y en la regulación y control de las ciencias médicas, en 1923 ya se hablaba de las formas jurídicas que abrían una grieta para lo que en 1926 sería la criminalización de los consumidores. Esta grieta, abierta por interés de farmacéuticos locales para distribuir culpas, va en la misma línea que las posturas marcadas a nivel internacional por la campaña moral norteamericana en la que se asocia el consumo de determinadas sustancias con la delincuencia: el vínculo perfecto para establecer la relación necesaria entre derecho y moral, que habilita la intervención estatal propia del paradigma en ciernes en materia de drogas.

Simultáneamente esta relación es la que convierte en multipropósito la política de drogas del momento: internamente satisface también las necesidades de atención al conflicto importado desde Europa y encarnado en la inmigración o en grupos marginales; mientras que, en política exterior, responde satisfactoriamente a las sugerencias norteamericanas, en un escenario diplomático tenso.

Cabe preguntarse entonces respecto de las políticas vigentes en la actualidad y de las dificultades que pueden presentarse a los intentos de reforma: ¿se trata de obstáculos implícitos provenientes de intereses internacionales?, ¿de la posición de los países del cono sur en los juegos de poder internacionales?, o bien ¿solo provienen de los intereses de las corporaciones médicas y de las empresas farmacéuticas?, ¿de sus necesidades en materia de regulaciones, beneficios y limitaciones en el accionar de otros agentes? También habría que hacer referencia a los debates disciplinarios dentro de las ciencias humanas: ¿solo se trata de factores psicológicos, o también comunitarios y sociales?

Así como la mirada histórica nos permitió analizar parte de los discursos presentes en las transformaciones legislativas de comienzos de siglo, creo necesario analizar en esta clave los argumentos, los actores y nodos del debate actual sobre los cambios legislativos de la región.

\section{AGRADECIMIENTOS}

Este trabajo es parte de la investigación "Prácticas y discursos sobre consumos no problemáticos de sustancias psicoactivas en jóvenes de clase media del AMBA: temporalidades redefinidas y sentidos del riesgo" conducente a mi tesis doctoral, que fue posible gracias a la Beca del Consejo Nacional de Investigaciones Científicas y Técnicas (CONICET) y a la dedicada dirección de la Dra. Ana María Mendes Diz y tutoría de la Dra. María Epele. Agradezco también a la Dra. Karina Ramacciotti, a la Lic. Melisa Paolino, la Dra. Noemí Lareo López y al Dr. Alberico Mangiavaca por las sugerencias realizadas a este trabajo. 


\section{NOTAS FINALES}

a. Tal como indica Maria Cecília de Souza Minayo (15), en sus orígenes, el análisis de contenidos de fuentes cualitativas -documentos, unidades de texto, etc.- ha estado asociado a la codificación numérica para un análisis cuantitativo posterior. Sin embargo, desde la década de 1960 la perspectiva cualitativa ha tomado impulso y adquieren relevancia los análisis que articulan los textos con factores contextuales y condiciones de producción de los mensajes (15 p.170). Entre las técnicas mencionadas por la autora, este trabajo utiliza el análisis de expresión, en el cual, sin entrar en un estricto análisis lingüístico, se "enfatiza la necesidad de conocer los trazos personales del autor del habla, su situación social y los datos culturales que lo moldean" (15 p.171). En este sentido, esta técnica me ha permitido atender a la trama argumentativa de Bard a través de las fuentes, las cuales han sido puestas en diálogo con otras y complementadas con interpretaciones historiográficas de otros autores. Con esto busqué una interpretación de sus argumentos sin caer en la impresión subjetiva. b. Fue imposible la consulta de los debates de la época en la Cámara de Diputados, ya que los archivos de la Biblioteca del Congreso de la Nación se encuentran fuera de consulta hasta finales del 2012.

c. Con la noción de paradigma moral-intervencionista se engloba al conjunto de acciones que guiarán el tratamiento político y social del fenómeno drogas en parte del siglo $X X$, dentro del que primará la intervención judicial por sobre la atención de la salud del consumidor. Por su parte, el modelo de atención sanitaria tendrá un corte paternalista mediante el cual se justificará la violación a la individualidad en nombre de la salud de terceros $(16,17)$.

d. Forman parte de los delitos contra la salud pública y están referidos a: (Art. 204) "suministro infiel de medicamentos y sus variantes"; (Art. 205) represión de las violaciones a las reglamentaciones impuestas por las autoridades para impedir la introducción o propagación de una epidemia, en este caso la toxicomanía.

\section{REFERENCIAS BIBLIOGRÁFICAS}

1. Bard L. Los peligros de la Toxicomanía: Proyecto de ley para la represión del abuso de los alcaloides. Buenos Aires: Talleres Gráficos Argentinos de L. J. Rosso y Cía.; 1923.

2. Aureano GR. La construction politique du toxicomane dans I'Argentine post-autoritaire. Un cas de citoyenneté à basse intensité [Internet]. 1997 [citado 13 dic 2011]. Disponible en: http://www.theses.umontreal.ca/ theses/pilote/aureano/these.html

3. Cattani H. El origen del control penal de las drogas. En: Cuñarro $M$, compilador. La política criminal de la droga. Buenos Aires: Ad-hoc Editor; 2010. p. 209-227.

4. Inchaurraga S. Drogas y políticas públicas: el modelo de reducción de daños. Buenos Aires: Espacio Editorial; 1999.

5. Kornblit AL, Mendes Diz AM. Nuevos estudios sobre drogadicción: consumo e identidad. Buenos Aires: Editorial Biblos; 2004.
6. Touzé G. Saberes y prácticas sobre drogas: el caso de la pasta base de cocaína. Buenos Aires: Federación Internacional de Universidades Católicas; 2006.

7. Touzé G, Goltzman P. Aportes para una nueva política de drogas: $\mathrm{V}$ y $\mathrm{VI}$ Conferencia Nacional sobre Políticas de Drogas. Buenos Aires: Intercambios, Universidad de Buenos Aires, Facultad de Ciencias Sociales; 2010.

8. Armus D. La ciudad impura: salud, tuberculosis y cultura en Buenos Aires, 1870-1950. Buenos Aires: Edhasa; 2007.

9. Ramacciotti KI. Estado, instituciones y actores: Reflexiones en torno a cómo pensar las intervenciones sociales del Estado. Revista de Estudios Marítimos y Sociales. 2010;3(3):193-204.

10. Ramacciotti KI. La política sanitaria del peronismo. Buenos Aires: Editorial Biblos; 2009.

11. Aureano G. Uso recreativo de drogas ilícitas: Una visión política. En: Cueto Caballero $M$, Cáceres $\mathrm{C}$, editores. La salud como derecho ciudadano: perspectivas y propuestas desde América 
Latina. Lima: Redess Jóvenes, Universidad Peruana Cayetano Heredia; 2003. p. 45-58.

12. Armus D. ¿Qué historia de la salud y la enfermedad? Salud Colectiva. 2010;6(1):5-10.

13. Armus D. La enfermedad en la historiografía de América Latina moderna. Asclepio. 2002; 54(2):41-60.

14. Denzin NK, Lincoln YS. The Sage handbook of qualitative research. 3rd ed. London: SAGE Publications; 2005.

15. Minayo MCS. El desafío del conocimiento: Investigación cualitativa en salud. Buenos Aires: Lugar Editorial; 2004.

16. Méndez V. Aspectos éticos de las políticas de reducción de daños en drogodependencias. En: Gestionando las drogas. Barcelona: Grup Igia; 2001. p. 89-98.

17. Colom Farran J. Análisis de las intervenciones en drogodependencias en el Estado español desde sus orígenes hasta la reducción de daños. En: Gestionando las drogas. Barcelona: Grup Igia; 2001. p. 49-58.

18. Ribeiro MM, Ribeiro M. Política mundial de drogas ilícitas: uma reflexão histórica. En: Moreira FG, Silveira DX, editores. Panorama atual de drogas e dependências. São Paulo: Atheneu; 2005. p. 457-468.

19. Vidal S. A regulamentação do cultivo de maconha para consumo próprio: uma proposta de redução de danos. En: MacRae E, Tavares LA, Rêgo $M$, organizadores. Toxicomanias: incidências clínicas e socioantropológicas. Salvador: EDUFBA, CETAD; 2009. p. 61-96.

20. Escohotado A. Historia general de las drogas. Madrid: Espasa Calpe; 1998.

21. Daskal R. Leopoldo Bard y la vida como compromiso: a 50 años de la edición de "Estampas de una vida. La fe puesta en un ideal. Llegar a ser algo". Educación Física y Deportes [Internet]. 2007 [citado 12 jul 2012];(108). Disponible en: http://www.efdeportes.com/efd108/leopoldobard.htm

22. Decreto 202/2003. Farmacopea argentina: Apruébase el texto del $1^{\circ}$ Volumen de la Séptima Edición. Boletín Oficial de la República Argentina [Internet]. 2003 [citado 12 jul 2012];111(30.172). Disponible en: http://www.facaf.org.ar/main/utiles/lafarmacia/Farmacopea.pdf

23. Vargas EV. Fármacos e outros objetos sóciotécnicos: notas para uma genealogia das drogas. En: Labate BC, Goulart SL, Fiore M, MacRae E, Carneiro $\mathrm{H}$, editores. Drogas e cultura: novas perspectivas. Salvador: EDUFBA; 2008. p. 41-64.

24. Ramacciotti KI, Cannellotto A, Luchtenberg E. Las instituciones sanitarias en la Argentina: Entre el clamor de las urgencias sociales y la planificación. Buenos Aires: Observatorio Argentino de Drogas (SEDRONAR), Universidad Nacional de General San Martín, Programa Mundos Contemporáneos; 2008.

25. Departamento Nacional de Higiene. Conferencia Sanitaria Nacional: Antecedentes, sesiones y conclusiones. Buenos Aires: Talleres Gráficos Editorial Argentina de Ciencias Políticas; 1923.

26. Bard L. Una encuesta internacional a propósito de la lucha contra la toxicomanía. Revista de la Asociación Médica Argentina. 1933:620-626; 1183-1189; 1322-1332. [Material de archivo]. Buenos Aires: Universidad de Buenos Aires, Biblioteca Central "Juan José Montes de Oca".

27. Davenport-Hines R. La búsqueda del olvido: Historia global de las drogas, 1500-2000. Barcelona: Fondo de Cultura Económica; 2004.

28. Rodrigues T. Tráfico, guerra, proibição. En: Labate BC, Goulart SL, Fiore M, MacRae E, Carneiro $\mathrm{H}$, editores. Drogas e cultura: novas perspectivas. Salvador: EDUFBA; 2008. p. 91-103.

29. Szasz TS. Our right to drugs: the case for a free market. New York: Syracuse University Press; 1996.

\section{FORMA DE CITAR}

Sánchez Antelo V. Primeros debates sobre legislación del uso de drogas en Argentina a comienzos del siglo XX: la propuesta del Dr. Leopoldo Bard y su contexto socio-histórico. Salud Colectiva. 2012;8(3):275-286.

Recibido el 11 de abril de 2012

Versión final presentada el 27 de agosto de 2012

Aprobado el 8 de septiembre de 2012 